\title{
Feature extraction of cotton plant height based on DSM difference method
}

\author{
Huanbo Yang ${ }^{1,2}$, Xing $\mathrm{Hu}^{1}$, Jing Zhao ${ }^{2}$, Yaohua $\mathrm{Hu}^{1,3,4^{*}}$ \\ (1. College of Mechanical and Electronic Engineering, Northwest A\&F University, Yangling, Shaanxi 712100, China; \\ 2. School of Agricultural Engineering and Food Science, Shandong University of Technology, Shandong 255000, China; \\ 3. Key Laboratory of Agricultural Internet of Things, Ministry of Agriculture and Rural Areas, Yangling, Shaanxi 712100, China; \\ 4. Shaanxi Key Laboratory of Agricultural Information Perception and Intelligent Service, Yangling, Shaanxi 712100, China)
}

\begin{abstract}
Spatiotemporal scale information of cotton plant height is closely related to cotton yield, and can provide a basis for irrigation, fertilization and topping of cotton in the field. In order to realize rapid monitoring of plant height during cotton growth period, this research obtained visible images of cotton initial bud stage, full bud stage and flowering stage by mounting an Unmanned Aerial Vehicle and splices them to obtain its Digital Surface Model. The mean plant height of cotton in each sampling area was calculated by combining the DSM difference method and the sample statistical method of the region of interest to generate a high-level distribution map of cotton plant height with soil background removed. The results showed that the extraction method of plant height of cotton based on DSM difference method is stable ( $R^{2}$ of cotton in three periods is higher than 0.750 , RMSE is less than $5 \mathrm{~cm}$; plant height model $R^{2}=0.849$ of cotton in the whole growth period). Therefore, DSM difference method can be used to achieve rapid and effective acquisition of cotton plant height, which is of great significance to guiding field cotton management. Finally, the vector files of pure cotton vegetation generated by the cotton TRVI vegetation index threshold method were used to crop the cotton DSM difference images, retaining the areas of only cotton vegetation in the test area, and generating the plant height class distribution maps of cotton at the first bud, full bud and flowering stages, so as to provide a theoretical basis for topping, irrigation and fertilization operations of cotton in the field.
\end{abstract}

Keywords: visible images; unmanned aerial vehicle; plant height; digital surface model

DOI: $10.33440 /$ j.ijpaa.20210401.151

Citation: Yang H B, Hu X, Zhao J, Hu Y H. Feature extraction of cotton plant height based on DSM difference method. Int J Precis Agric Aviat, 2021; 4(1): 59-69.

\section{Introduction}

Cotton is a major cash crop in the world ${ }^{[1]}$, a commodity involving two major industries, textile and agriculture, and the main source of income for 100 million cotton farmers in China. In recent years, cotton planting area has significantly decreased in China. Complex cotton planting and management procedures, high cost and long growth period are the main reasons for the decrease of cotton planting area. Rapid non-destructive monitoring of crop growth and accurate prediction of yield are necessary means to achieve accurate management of field crops. How to carry out accurate and effective field cotton management is of great significance to the development of cotton industry.

Remote sensing technology obtains electromagnetic wave information of vegetation radiation and reflection by means of sensors in a non-contact way to realize monitoring and identification of targets ${ }^{[2]}$. At present, remote sensing monitoring applications in agriculture mainly include pest identification ${ }^{[3,4]}$, weed monitoring ${ }^{[5-7]}$, soil composition monitoring ${ }^{[8,9]}$, crop quality identification $^{[10-12]}$ and crop growth monitoring ${ }^{[13,14]}$. Plant height is an important parameter for monitoring crop growth trend. Plant

Received date: 2021-02-19 Accepted date: 2021-03-26

Biography: Huanbo Yang, $\mathrm{PhD}$ candidate, research interests: application of UAV remote sensing technology in agriculture, Email: 1332616134@qq.com; Xing Hu, research interests: rapid acquisition of agricultural information ,Email: hallyhu@nwafu.edu.cn; Jing Zhao, PhD, Associate Professor, research interest: agricultural remote sensing technology and intelligent detection, Email: zbceozj@163.com.

* Corresponding author: Yaohua Hu, PhD, Professor, research interests: mechatronics and quick acquisition of agricultural information. Mailing Address: College of Mechanical and Electronic Engineering, Northwest A\&F University, Yangling 712100, China. Email: huyaohua@nwsuaf.edu.cn. height information of crops is closely related to its own lodging resistance, biomass and yield information ${ }^{[15,16]}$. Obtaining plant height of cotton by Unmanned Aerial Vehicle (UAV) remote sensing technology is of great significance to guide farmers in field cotton topping operation. At present, the common extraction methods of plant height of crops are mainly realized by ground remote sensing technology and aerial remote sensing technology. Bendig et al. succeeded in obtaining barley plant height through UAV visible remote sensing platform and established regression model between barley plant height value and barley biomass ${ }^{[17]}$; Yaxiao Niu obtained the point cloud data in the maize image by using Pix4DMapper software based on the visible remote sensing platform independently developed, and successfully extracted the plant height information of maize, $R^{2}$ and RMSE are 0.90 and $0.12 \mathrm{~m}$, respectively. The regression model of maize biomass was built by combining the plant height obtained from point cloud data with the vegetation index of visible band, and good results were obtained $^{[18]}$.

Traditional monitoring of crop plant height based on ground remote sensing data often requires professional field sampling to obtain remote sensing data of crops. This method is limited by physical and human conditions and has certain limitations in estimating crop yield in a wide range of fields. At present, the resolution of satellite remote sensing data for civilian use is low, and the rainy weather will cause strong interference to the acquisition of satellite data. Therefore, the advantage of satellite data monitoring can not be brought into play in field-scale production estimation. With the rapid development of UAV remote sensing technology, its speed and flexibleness, high resolution of acquiring remote sensing images is very suitable for the research related to growth monitoring and yield prediction of 
cotton $^{[19]}$. Therefore, in this research, the UAV platform was selected for research related to cotton growth monitoring.

Nowadays, crop growth monitoring and yield estimation based on UAV remote sensing technology are mainly realized by mounting multi-spectral and hyperspectral sensors on UAV) platform. Jinya Su et al. ${ }^{[20]}$ have put forward an automatic rust detection framework by integrating UAV remote sensing, multispectral imaging and U-Net deep learning network; Jinya Su et al. ${ }^{[21]}$ have developed an automatic yellow rust detection system using a random forest classifier based on the marked unmanned aerial multispectral images. But UAVs with hyperspectral and multispectral sensors are difficult to apply in general scientific research institutes and universities because of their high price ${ }^{[22]}$, frequent maintenance and tedious data processing in the later stage, and even more difficult to popularize for ordinary farmers. Currently, most UAVs in the mainstream market are equipped with visible light cameras. Compared with multi-spectral and hyperspectral cameras, visible cameras contain less band information, but they are characterized by high resolution, low cost and easy maintenance. Due to the complex vegetation characteristics of cotton, there are few researches on cotton plant height extraction from UAV visible images. Therefore, this study carried out the relevant research on cotton plant height monitoring on UAV, and generated the plant height level distribution image of cotton vegetation, in order to provide a theoretical basis for cotton field management.

Based on the existing technical approaches, the research objectives were:

(1) To establish an index threshold method for cotton vegetation coverage extraction model;

(2) To establish cotton plant height extraction model based on DSM difference method using cotton visible light image;

(3) To obtain generate high-level plant height distribution map of cotton in each period by using vector file.

\section{Materials and methods}

\subsection{Experimental Design}

In this research, eleven varieties of cotton cultivated by the Cotton Research Center of Shandong Province were studied, and remote sensing image data were acquired by using the UAV of the Mavic 2pro in five periods: bare ground, initial bud, full bud, flowering and boll stages. The plant heights of cotton at the initial bud, full bud and flowering stages were extracted by Digital Surface Model (DSM) differential method, and the plant heights obtained by DSM differential method were verified by using the ground-measured cotton plant heights to verification the plant height model of cotton, and the generated cotton vector files were cropped to generate the plant height distribution map of pure cotton vegetation for topping, irrigation and fertilization operations of cotton in the field. The research content and technical route of this research were shown in Figure 1.

The experimental field is located in Linqing Cotton Research Institute of Shandong Cotton Research Center, northwest of Shandong Province, and belongs to continental monsoon climate. eleven kinds of cotton planted in the test area are high-yield and lodging-resistant high-quality varieties independently cultivated by Shandong Cotton Research Center. The area of the test field is about $1333 \mathrm{~m}^{2}$. In order to alleviate the influence of terrain on cotton seeding and irrigation, before cotton seeding, laser grader is used to carry out remediation. The sowing method is machine-seeding with $0.78 \mathrm{~m}$ row spacing and $0.10 \mathrm{~m}$ plant spacing. The method is non-film planting with 4 rows per variety and 3 random repeats. In order to facilitate geometric correction of cotton visible image and acquisition of ground data in the later period, ground control points need to be set during aerial photography. The ground control points are composed of four geometric reference boards $(80 \mathrm{~cm} \times 80 \mathrm{~cm}$ black and white grid boards). Real-time kinematic (RTK) carrier phase difference technology is used to record the longitude, latitude and elevation information of the center points of four reference plates. The ground data acquisition method uses standard sample acquisition, i.e. placing a red flag as the marker of ground sampling points in the corresponding sampling point area, which facilitates data acquisition in the test area for several periods and establishes the connection between remote sensing image of UAV and ground data. The coordinates of the control points were shown in Table 1 and the top view of the test site is shown in Figure 2.

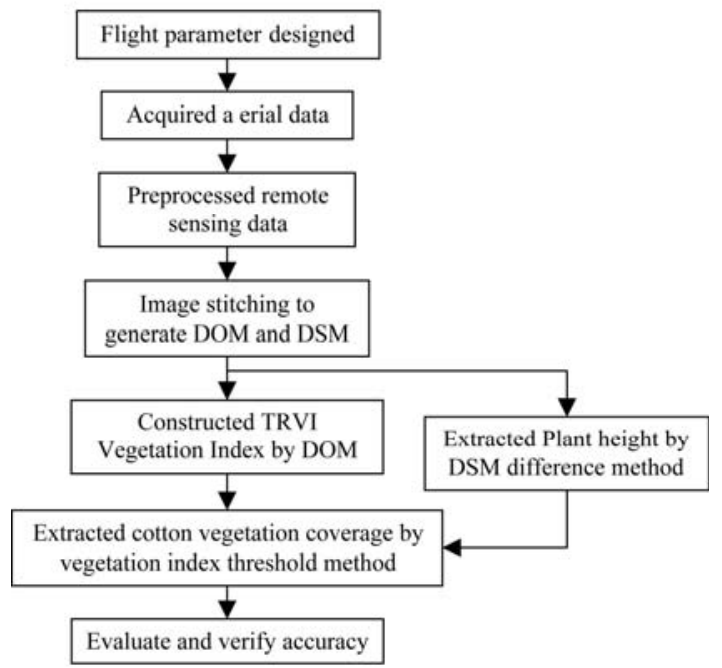

Figure 1 Technical route of cotton plant height feature extraction model

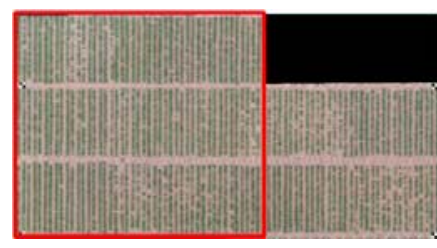

a. A panorama of the test field

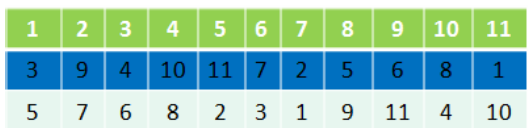

c. A distribution map of cotton varieties

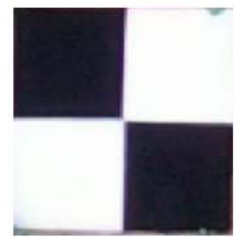

b. Reference plate for ground geometry correction

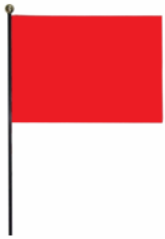

d. A red flag symbol in the sampling area
Figure 2 Schematic diagram of test area distribution

Table 1 Coordinates of ground control points

\begin{tabular}{cccc}
\hline Position & Latitude & Longitude & Altitude \\
\hline $\mathrm{P}_{1}$ & 36.803228 & 115.694449 & 24.463 \\
$\mathrm{P}_{2}$ & 36.803408 & 115.694450 & 24.461 \\
$\mathrm{P}_{3}$ & 36.803407 & 115.695096 & 24.501 \\
$\mathrm{P}_{4}$ & 36.803227 & 115.695096 & 24.453 \\
\hline
\end{tabular}

\subsection{Data Acquisition}

\subsubsection{Remote Sensing Data Acquisition}

Visible light images of bare cotton fields (filmed on May 22, 2019), initial bud stage (filmed on June 22, 2019), full bud stage 
(filmed on July 03), flowering stages (filmed on July 13, 2019) and boll stage (filmed on July 26, 2019) were obtained by UAV Mavic 2pro during the test. The RTK equipment is the module of Dajiang spirit 4rtk version, and its hovering accuracy is $1 \mathrm{~cm}+1$ ppm horizontally and $1.5 \mathrm{~cm}+1 \mathrm{ppm}$ vertically. The mobile DJIGO 4 software was used to test the UAV performance parameters and to plan the route of the test area through Artizure software after making sure there are no errors. Altizure Software is the most well-known modeling tool in China at present. It can work at high altitude with UAV and plan one ortho-jet route and four inclined routes at the same time. It also has the settings of automatically adjusting the cloud platform angle, taking photos independently, automatically recording flight progress, changing power and flying continuously, adjusting overlap, inclination angle, flying speed, etc., and customizing camera model. Support domestic coordinate correction and other functions. In order to ensure effective splicing of subsequent Cotton Remote Sensing images, the bypass and heading overlap in the route were set at $90 \%$, the flight height of UAV was set to be $30 \mathrm{~m}$ above ground. Before route planning, ensure that UAVs on the route were not disturbed by high-voltage wires, trees, towers and other objects. In order to ensure sufficient lighting conditions and small shadow area, UAV visible light data collection is generally carried out around 12:00 noon. According to the light intensity, set the exposure time and aperture size of the camera through debugging, as shown in Table 2, to obtain the best image quality.

Table 2 Parameter setting of UAV Mavic 2pro aerial (manual setting)

\begin{tabular}{lc}
\hline \multicolumn{1}{c}{ Parameter } & Numerical value \\
\hline Focal length & $\mathrm{f} / 5.6$ \\
Valid pixels & 20 million \\
ISO & 200 \\
Side overlap & $90 \%$ \\
Direction overlap & $90 \%$ \\
White balance & Sunny mode \\
Shutter time & $1 / 800$ \\
Flying height & $30 \mathrm{~m}$ \\
\hline
\end{tabular}

\subsubsection{Obtaining the measured data of ground cotton}

(1) Measurement of cotton plant height data

The cotton plant height in the test area was acquired by tape. In order to reduce the influence of cotton growth on plant height extraction, the cotton plant height data collection was carried out on the same day as the UAV aerial data collection. The height from the canopy to the surface of four cotton plants with similar growth in each sampling area was measured with tape. The area of each sampling area was $6 \mathrm{~m}^{2}$, and four cotton plants with uniform growth were selected. The average plant height of 4 cotton plants was taken as the observation value of plant height in the experimental plot.

\subsection{UAV visible light images stitching}

In the above five stages, 385 visible light images of cotton in each stage were obtained by using UAV mavic2pro. The area of single image taken by UAV was limited, and image stitching can obtain the remote sensing image of the whole test area. Agisoft PhotoScan Professiona software was selected to stitch the images of five periods of cotton, and finally generate Digital Orthophoto Map (DOM) and DSM of the test area. This software is a UAV aerial photography processing software developed in Russia. According to the latest multi-view three-dimensional reconstruction technology, It can process images of various formats, and has the functions of image mask addition and distortion elimination. It can process route vulnerability data smoothly and generate professional photogrammetric data ${ }^{[22,23]}$ through a fully automatic process. The image splicing process is as follows:

(1) Import the visible cotton images captured by UAV aerial photography into the software, and eliminated the images taken during takeoff and landing of UAV.

(2) Set the software parameters of Agisoft PhotoScan Professiona and corrected the camera.

(3) Aligned photos, generated grid, added ground control points, optimized camera parameters, adjusted ground control point error accuracy, generated grid, and generated texture operations.

(4) Generated digital surface model and orthophoto. Figure 3 shows the splicing process of visible light images of cotton acquired by UAV in PhotoScan Professiona software.

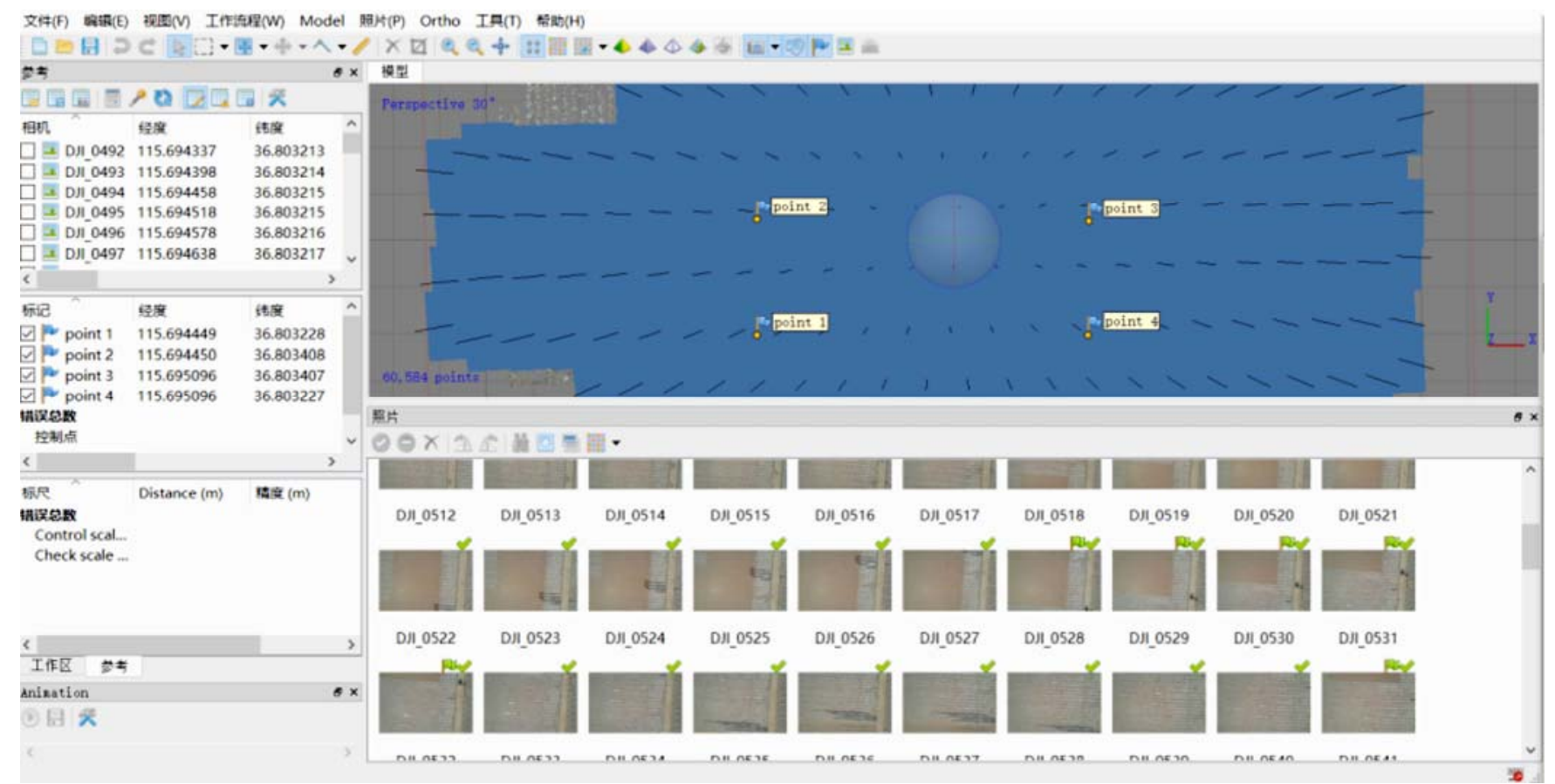

Figure 3 Stitching process of visible light images of cotton acquired by UAV 


\section{4 Extraction of remote sensing factors}

\subsubsection{Construction of visible light vegetation index}

In order to reduce the influence of shadow on vegetation coverage extraction in full bud, flowering and boll stages of cotton, the spectral characteristics of cotton, soil and shadow in full bud orthophoto images obtained by UAV were analyzed. For each feature, 80 representative regions were obtained, and the eigenvalues (including maximum, minimum, average and standard deviation) of the above three features in red, green and blue bands were calculated. The average value was selected as the overall difference index of the three bands of the three ground objects, and the standard deviation was introduced to check the fluctuation range of each band. The statistical results were shown in Table 3.

It can be seen from Table 3 that the gray values of cotton and soil in the blue band and red band were crossed, and the gray values of cotton vegetation and soil in the green band are crossed. It was difficult to distinguish cotton vegetation from soil and shadow by a single band. Therefore, this research constructs a scatter map of two combinations of red, green and blue gray values of cotton flower, soil and shadow. As shown in Figure 4, the vegetation index was constructed based on the obvious boundary between cotton and soil scattered points, in which the green part represents cotton vegetation, the blue part represents shadow, and the yellow part represents soil.

Table 3 Cotton vegetation, soil and shadow pixel value difference in blue, green and red bands

\begin{tabular}{ccccccc}
\hline \multirow{2}{*}{$\begin{array}{c}\text { Feature } \\
\text { Type }\end{array}$} & $\begin{array}{c}\text { Pixel value in blue } \\
\text { band }\end{array}$ & \multicolumn{2}{c}{$\begin{array}{c}\text { Pixel value in green } \\
\text { band }\end{array}$} & \multicolumn{2}{c}{$\begin{array}{c}\text { Pixel values in red } \\
\text { band }\end{array}$} \\
\cline { 2 - 7 } & $\begin{array}{c}\text { Mean } \\
\text { value }\end{array}$ & $\begin{array}{c}\text { Standard } \\
\text { deviation }\end{array}$ & $\begin{array}{c}\text { Mean } \\
\text { value }\end{array}$ & $\begin{array}{c}\text { Standard } \\
\text { deviation }\end{array}$ & $\begin{array}{c}\text { Mean } \\
\text { value }\end{array}$ & $\begin{array}{c}\text { Standard } \\
\text { deviation }\end{array}$ \\
\hline Cotton & 95.891 & 35.193 & 134.135 & 36.198 & 64.071 & 31.715 \\
Soil & 197.736 & 19.260 & 167.807 & 19.904 & 127.390 & 22.280 \\
Shadow & 58.200 & 12.962 & 57.058 & 11.127 & 44.067 & 10.948 \\
\hline
\end{tabular}

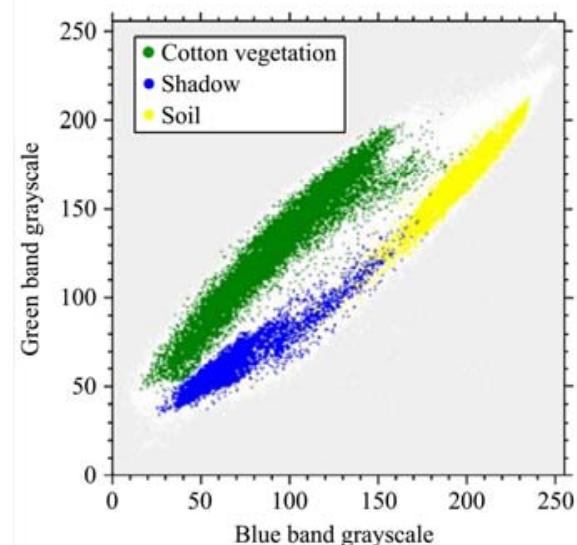

a. Blue \& green band grayscale

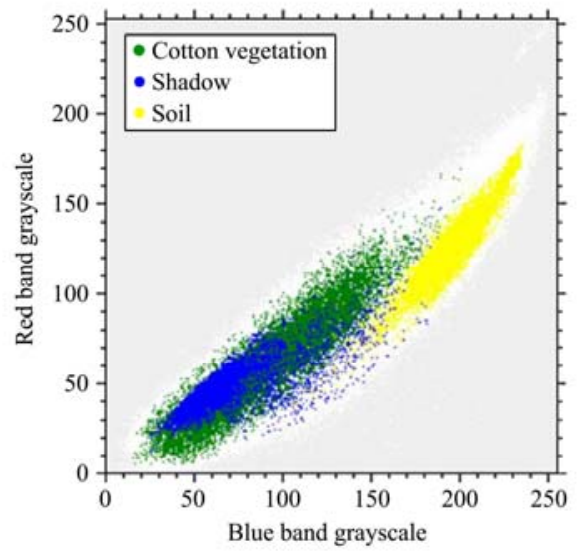

b. Blue \& red band grayscale

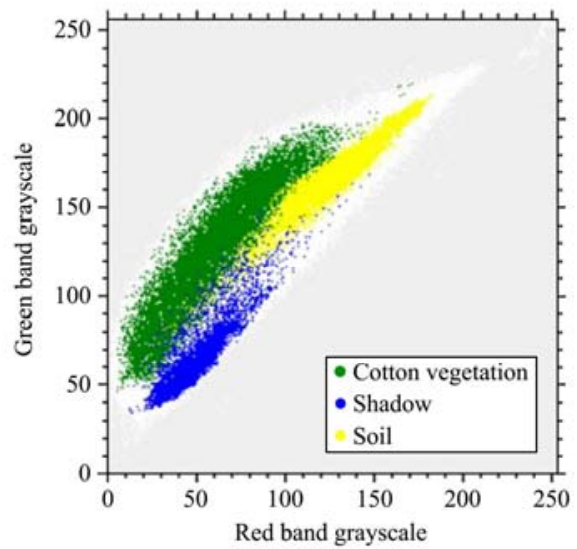

c. Red \& green band grayscale

Figure 4 Scatters of cotton, soil and shadow

From Figure 4, it can be seen that there were obvious dividing lines in the 2 scatter plots with red \& green as the characteristic values and cotton, soil and shadow as the indicated quantities. Cotton was basically distributed at the top left of the boundary line, and soil and shadow were basically distributed at the bottom right of the boundary. The scatter coordinates of the boundary lines were extracted by visual interpretation, and 50 boundary points were read on the two scatter maps for fitting to obtain the expressions of the feature combination parameters, and the fitting results were shown in Figure 5 red tend vegetation index (TRVI), the formula was shown in (1), and the gray-scale image was shown in Figure 6.

$$
T R V I=G-0.899 R-22.623
$$

and the gray image was shown in Figure 6.

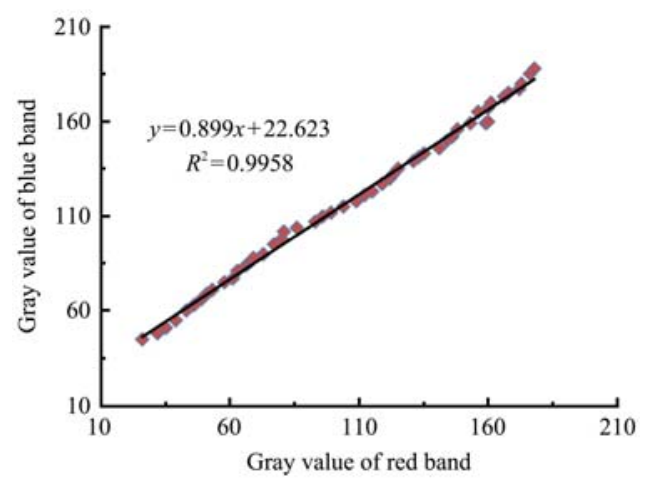

Figure 5 Fitting results of TRVI vegetation index

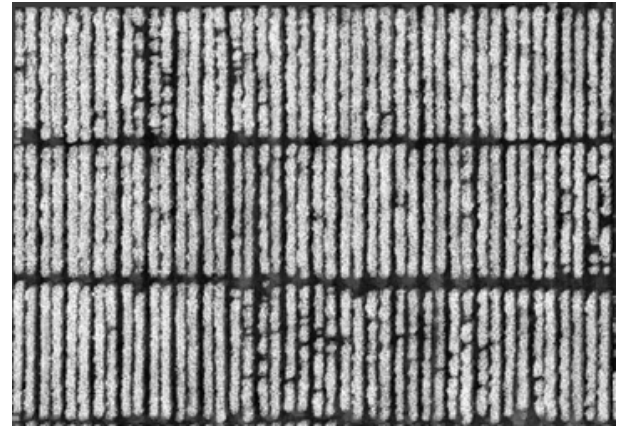

Figure 6 Grayscale images of TRVI

2.4.2 Extraction of cotton vegetation coverage based on vegetation index threshold method

Researchers based on the DOM and DSM generated from the UAV images have explored the changes of vegetation coverage more accurately on the landscape scale, thus greatly reducing the phenomenon that vegetation coverage is overestimated or underestimated. Most of the methods used are threshold method and vegetation index method. OTSU algorithm is an efficient binarization algorithm proposed by Japanese scholar OTSU in 1979 It is an adaptive threshold determination method for image segmentation and is the optimal segmentation in the sense of least squares. Its basic principle is to assume that the detection image is composed of foreground and background parts. The threshold value is selected by statistical calculation, so that the threshold can distinguish foreground and background to the maximum extent. However, its disadvantage is that it is very sensitive to noise and 
target size, and only produces good segmentation results for images with single peak of inter-class variance. Based on TRVI gray scale image, draw its gray scale histogram as shown in the Figure 7.

It can be seen from the graph that the gray histogram shows three peaks, and the interference area has peaks on the gray histogram. As shown by the TRVI gray histogram, it is not possible to separate the soil from the vegetation by the Otsu method. Therefore, this study proposed a threshold vegetation index method.

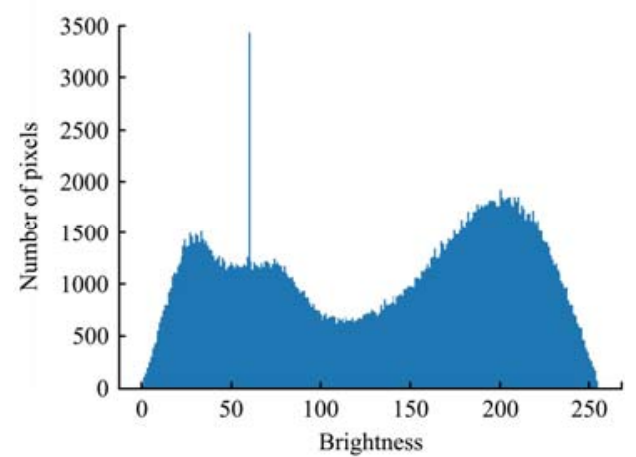

Figure 7 Gray Histogram of TRVI

The vegetation index threshold method combines the intersection method of vegetation index time series diagram and the sample statistical method. According to the intersection method of vegetation index sequence diagram ${ }^{[24]}$, the crop experimental area was composed of vegetation and soil. With the continuous growth of crops, the number of vegetation pixels in the experimental field was increasing, and the increase of the number of vegetation pixels came from the decrease of the number of soil pixels. Then the intersection of vegetation index of high vegetation coverage area and low vegetation coverage area can be used as the threshold of crop vegetation coverage extraction. The sample statistical method ${ }^{[25]}$ carries out statistical analysis on the basis of visual interpretation, and then determined the extraction threshold of crop vegetation coverage. If the test area in a certain period was supervised and classified into vegetation and soil, the statistical histogram of vegetation index of soil and vegetation was calculated respectively, and the intersection of vegetation index was used as the extraction threshold of crop vegetation coverage, it had good effect ${ }^{[26]}$. According to the histogram characteristics of visible band vegetation index of cotton vegetation and soil, the classification threshold of cotton vegetation and soil pixel was determined by combining supervised classification and vegetation index, and the determined threshold was used to extract cotton vegetation coverage. The specific process was shown in Figure 8.

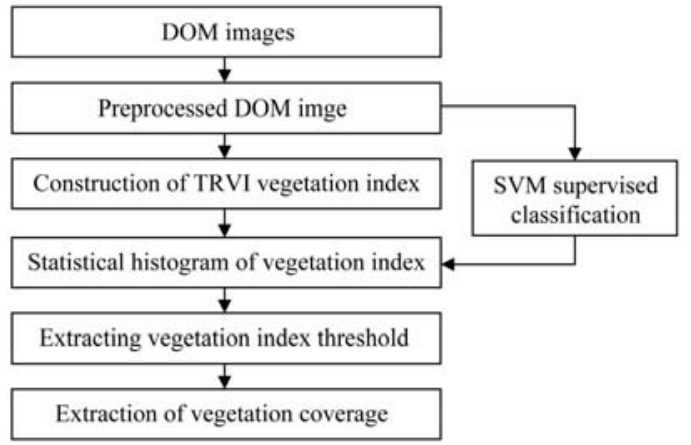

Figure 8 Flow chart of cotton FVC Extraction based on vegetation index threshold method

With the continuous growth of cotton, there were a lot of shadows in the visible light remote sensing image of the experimental area after the cotton initial bud stage, and the environment of the experimental field became more complex. If only the thresholds determined by the growth stage of cotton at the first bud stage were used for the extraction of vegetation cover at the bloom, flowering and boll stages of cotton, there will be large errors. The extraction threshold of vegetation coverage determined by the combination of supervised classification and vegetation index was only used for the extraction of vegetation coverage in the growth stage of cotton and the initial bud stage, and the extraction threshold of vegetation coverage determined in the full bud stage was used for the extraction of vegetation coverage in the full bud stage, flowering stage and boll stage.

In order to improve the efficiency of extracting the threshold of cotton vegetation coverage by combining supervised classification and vegetation index, some regions were cut on the orthophoto images of the test area at the initial and full bud stages of cotton for support vector machine supervised classification. Support Vector Machine (SVM) is a new statistical machine classification method proposed by Vapnic, which can effectively solve the problems of small sample, nonlinear and high dimension, and has strong generalization ability ${ }^{[27]}$. The confusion matrix method is a supervised classification method proposed by Congalton in 1991. The confusion matrix can not only calculate the total accuracy, Kappa coefficient index and other indicators representing the overall accuracy $^{[28]}$, but also calculate the producer accuracy, user accuracy and other indicators representing the classification effect of a single category. The confusion matrix can be used as a high-quality classification method. Therefore, it was suggested to be the standard method for the accuracy test of remote sensing classification.

The process of SVM supervised classification is as follows.

(1) The original orthophotos of the cotton test field at the early bud stage and the full bud stage were spliced, and 80 sample regions of cotton and soil on the orthophotos of the test field were selected as training sets for support vector machine supervised classification by the region of interest method (ROI) on the spliced images, respectively.

(2) The separability of the selected samples was calculated. Generally, the two parameters of the separability are between 0 and 2. If the separability between samples is higher than 1.9 , it means that the sample has good separability and is qualified. According to the ENVI software, the separability of samples at the initial bud stage was 1.997, and that at the full bud stage was 1.9986.

(3) The experimental fields were classified by SVM, and the same Radial Basic Function was used as kernel function.

(4) Eighty cotton and soil samples from another area of the test field were selected for confusion matrix validation, and the support vector machine classification results are shown in Figure 9, where the white part indicates soil and the green part indicates cotton vegetation.

(5) Using confusion matrix to verify the classification accuracy of cotton, the overall classification accuracy of cotton in initial bud stage is $99.412 \%$, Kappa coefficient is 0.990 , the overall classification accuracy of cotton in full bud stage is $95.517 \%$, Kappa coefficient is 0.990 . The verification results of the confusion matrix at the initial bud stage are shown in Table 4, and the verification results of the confusion matrix at the full bud stage are shown in Table 5. From the verification results of the confusion matrix, it can be seen that the SVM supervised classification of cotton has achieved good results. 


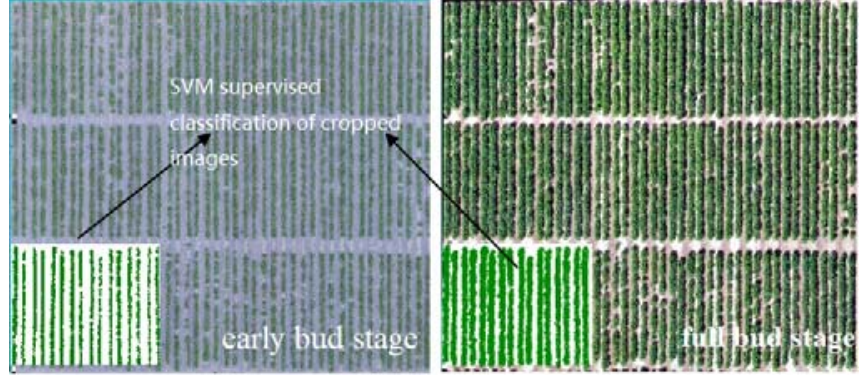

Figure 9 Support vector machine classification results of cotton during the early bud and full bud stages

Table 4 Verification results of confusion matrix for cotton SVM classification during initial budding period

\begin{tabular}{lcccc}
\hline \multicolumn{1}{c}{ Type } & $\begin{array}{c}\text { Soil } \\
\text { /pixel }\end{array}$ & $\begin{array}{c}\text { Cotton } \\
\text { /pixel }\end{array}$ & $\begin{array}{c}\text { Total samples } \\
\text { /pixel }\end{array}$ & $\begin{array}{c}\text { User accuracy } \\
\text { /\% }\end{array}$ \\
\hline Soil & 25259 & 275 & 25534 & 99.96 \\
Cotton & 11 & 24995 & 25006 & 98.92 \\
Total samples/pixel & 25270 & 25270 & 201480 & \\
Producer accuracy/\% & 99.96 & 98.91 & & \\
\hline
\end{tabular}

Table 5 Verification results of confusion matrix for cotton SVM classification during budding period

\begin{tabular}{lcccc}
\hline \multicolumn{1}{c}{ Type } & $\begin{array}{c}\text { Soil } \\
\text { /pixel }\end{array}$ & $\begin{array}{c}\text { Cotton } \\
\text { /pixel }\end{array}$ & $\begin{array}{c}\text { Total samples } \\
\text { /pixel }\end{array}$ & $\begin{array}{c}\text { User accuracy } \\
\text { /\% }\end{array}$ \\
\hline Soil & 18949 & 190 & 19139 & 99.83 \\
Cotton & 51 & 30680 & 30731 & 99.01 \\
Total samples/pixel & 19000 & 30870 & 201480 & \\
Producer accuracy/\% & 99.73 & 99.38 & & \\
\hline
\end{tabular}

The vegetation index values of soil and cotton vegetation were taken as abscissa, and the number of pixels was taken as ordinate. The statistical histogram of soil and cotton vegetation were drawn. The intersection of the histogram of cotton vegetation and soil 2 vegetation index under the coordinate system were taken as the classification threshold of cotton vegetation and soil. The statistical histogram of 2 vegetation index were shown in Figures 10 and 11.

The vegetation cover extraction thresholds for the TRVI of cotton at the initial bud stage determined by the above vegetation index threshold method were -0.082 ; the vegetation cover extraction thresholds for the cotton at the full bud, flowering and boll stages were -4.861. The vegetation cover extraction thresholds for the corresponding periods of cotton determined in the above cropped images were used for the vegetation cover extraction of the whole experimental area. The results of vegetation cover extraction for cotton at the initial bud stage, full bud stage, flowering stage and boll stage obtained by using the method of Equation (2) were shown in Table 6.

$$
F V C=\frac{N_{\text {cotton }}}{N_{\text {cotton }}+N_{\text {soil }}}
$$

where, $N_{\text {cotton }}-$ Statistics of cotton pixels; $N_{\text {soil }}-$ Statistical number of soil pixels.

Table 6 Extraction of cotton FVC based on TRVI threshold

\begin{tabular}{cc}
\hline Cotton growth stage & Vegetation coverage/\% \\
\hline Initial bud stage & 29.0538 \\
Full bud stage & 55.9569 \\
Flowering stage & 78.70 \\
Boll stage & 91.7446 \\
\hline
\end{tabular}

In this research, TRVI vegetation index threshold method was selected to extract the vegetation coverage of cotton in four periods, and the extraction results were shown in Figure 12.

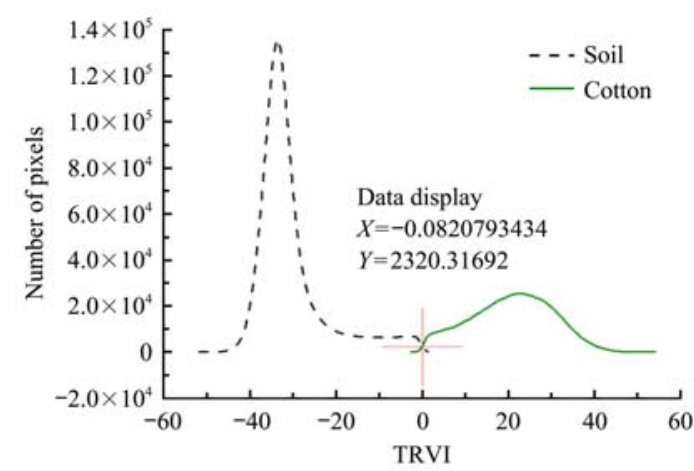

Figure 10 Threshold extraction results of FVC during initial budding stage of cotton

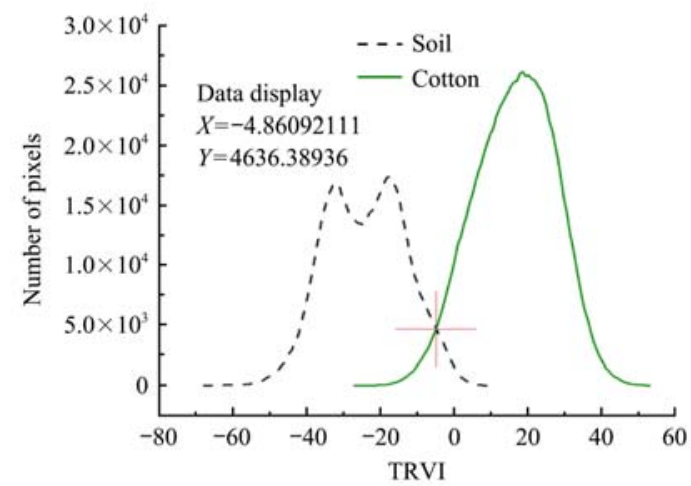

Figure 11 Threshold extraction results of FVC during budding stage of cotton

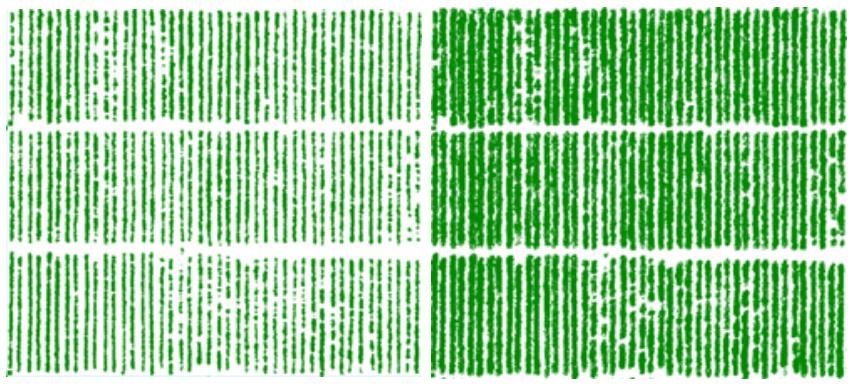

a. Initial bud stage

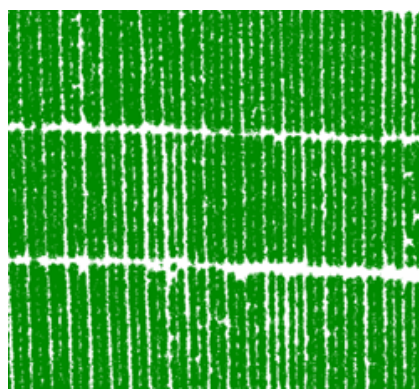

c. Flowering stage b. Full bud stage

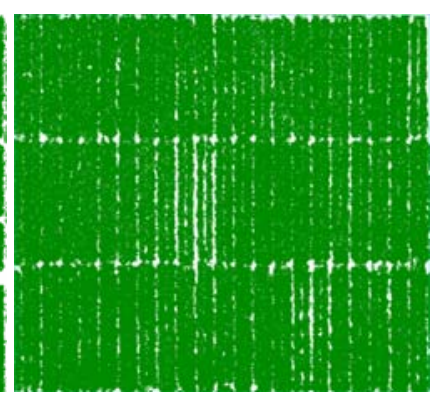

d. Boll stage
Figure 12 Extraction results of cotton FVC in four periods based on TRVI

\section{Results and discussion}

3.1 Extraction of cotton plant height based on DSM difference method

Since DSM was generated based on remote sensing data collected in different periods, in order to ensure that it is under the common reference coordinate system, the ground control point method was used to stitch the images while the field was leveled by laser grader before planting. Leveling the field is not only 
beneficial to field management such as fertilization and irrigation in the later stage of cotton, but also can ensure the accuracy of the DSM difference method to extract the height of cotton plants. Geometric errors will inevitably occur in the image splicing process of cotton in the later stage. Elevation difference calculation in Arcmap software was calculated with coordinates as corresponding points. The existence of geometric errors will affect the extraction accuracy of plant height by DSM difference method. Smooth bare ground can minimize the error of cotton plant height extracted by DSM difference method. Before cotton emergence, the test area was bare soil area to acquire its UAV visible image. The obtained UAV visible images were spliced by Agisoft PhotoScan Professiona software combined with ground control point to generate DSM in the test area, which was marked as $\mathrm{DSM}_{0}$ and used as the reference surface of cotton plant height by DSM difference method. DSM of cotton initial bud stage, full bud stage and flowering stage were obtained by the same method, marked as DSM1, DSM 2 and $\mathrm{DSM}_{3}$ respectively. The difference between $\operatorname{DSM}_{i}(1,2,3)$ and $\operatorname{DSM}_{0}$ was calculated in Arcmap software to obtain the plant height of cotton, as shown in formula (3).

$$
H_{i}=D S M_{i}-D S M_{0}
$$

The extraction principle of plant height was shown in Figure 13.

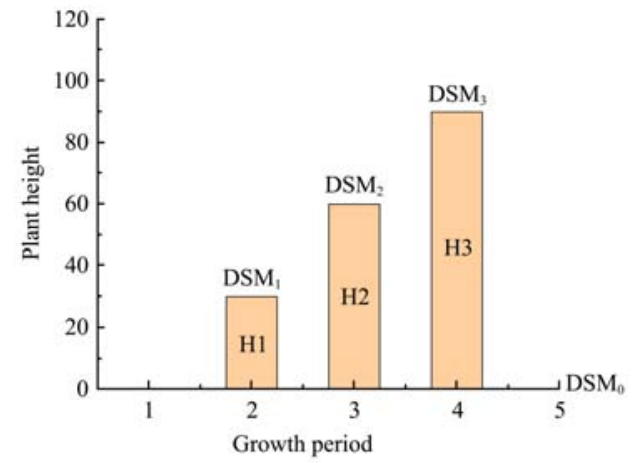

Figure 13 The principle of cotton plant height extraction

Visible images of test area acquired at bare ground, initial bud stage, full bud stage and flowering stage were spliced and cut with ground control point GCP to generate corresponding DSM. Elevation statistics histogram of cotton in four stages were shown in Figure 14.

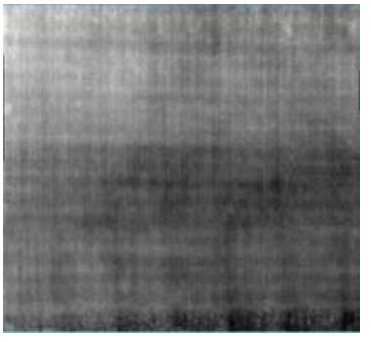

a. Bare ground

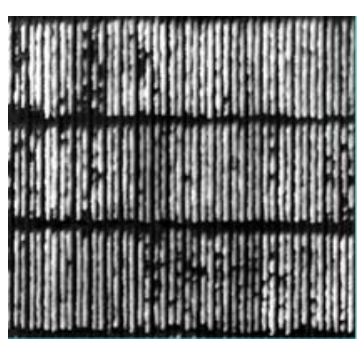

c. Full bud stage

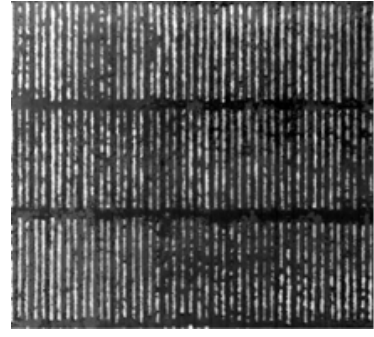

b. Initial bud stage

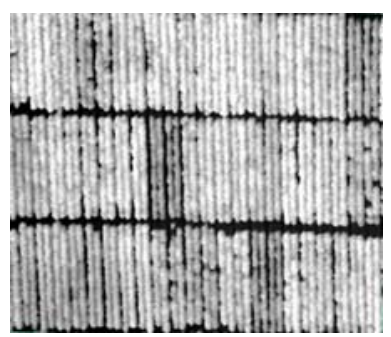

d. Flowering stage
Figure 14 DSM distribution maps of cotton in four periods

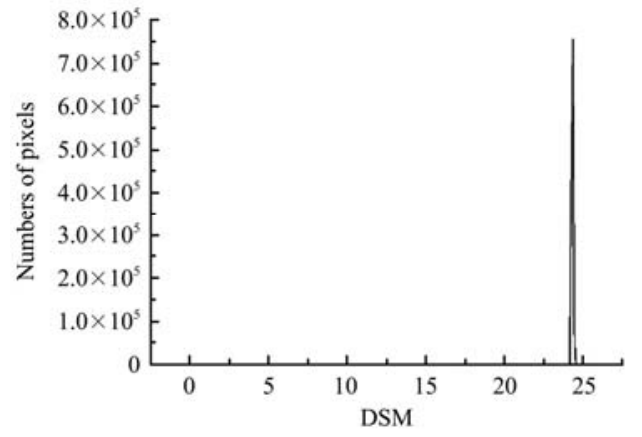

a. Bare ground

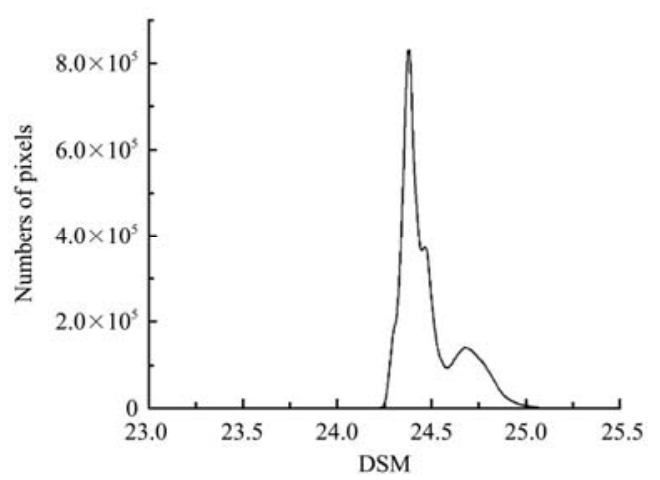

b. Initial bud stage

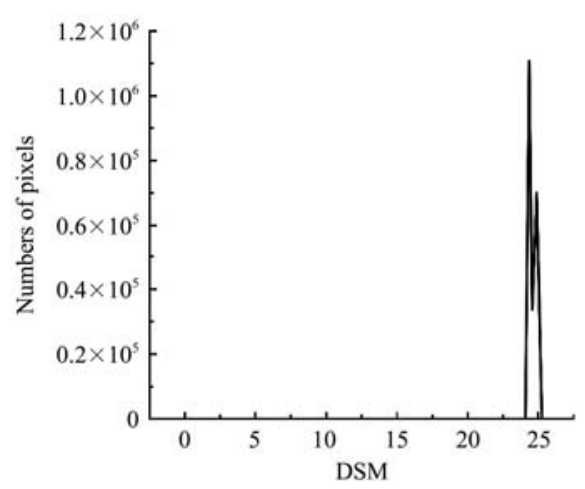

c. Full bud stage

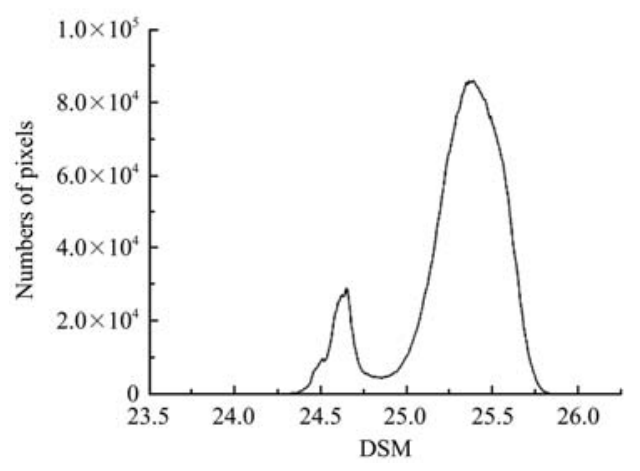

d. Flowering stage

Figure 15 DSM statistical histograms of cotton in four period

From the DSM grayscale images and DSM statistical histograms of four periods of cotton, it can be seen that the DSM values of the experimental area in the bare ground period were concentrated around the elevation of the ground control points, and the image was a steep single peak shape. It can be seen that the terrain of the cotton bare ground period was flat, which was consistent with the results of the experimental area before cotton sowing. The DSM statistical histograms of cotton at initial bud stage, full bud stage, and flowering stage basically conform to the bimodal characteristics, because the cotton DSM images were composed of cotton vegetation and soil, so the DSM statistical 
histograms of cotton at the above three stages show obvious bimodal distribution, and with the growth of cotton, the number of cotton pixels in the statistical histograms increases continuously, which conformed to the growth characteristics of cotton in the corresponding period. Therefore, the DSM image in Figure 13 can be used to extract the plant height of cotton in three periods.

The plant height of cotton was calculated by using the difference between the DSM of initial bud stage, full bud stage and flowering stage and the DSM of bare ground stage in the experimental area. The whole process was carried out in ArcMap software. The DSM difference calculation results of four cotton stages were shown in Figure 16. The DSM difference calculation results of corresponding periods in the sampling area were counted by the way of region of interest, and the mean value of the statistical results was taken as each sampling area. The plant height of cotton in three periods is shown in Figure 16.

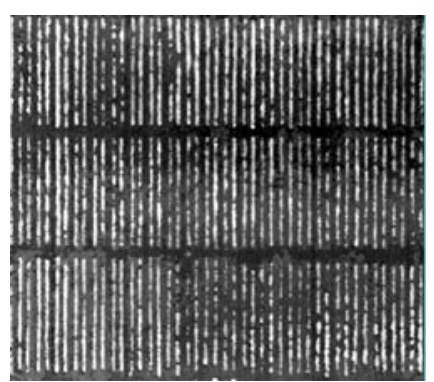

a. Initial bud stage

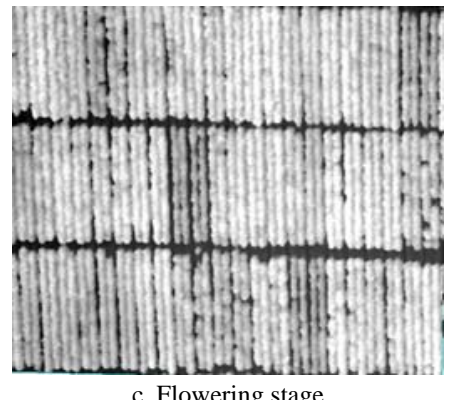

c. Flowering stage

Figure 16 Calculation results of Cotton DSM difference

\subsection{Verification of cotton plant height extraction accuracy based on DSM difference method}

Before cotton emergence, the test area was a bare soil area, and its UAV visible images were acquired, and the acquired UAV visible images were stitched by Agisoft PhotoScan Professiona software combined with ground control points to generate DSM of the test area and marked as DSM0, which was used as the reference plane for cotton plant height extraction by DSM difference method. After the visible images were obtained by aerial photography, the difference between the coordinates of the correction plate under GPS and those under RTK was calculated, and if its position deviation was less than $5 \mathrm{~cm}$, the DSM generated by its stitching was proved to be accurate.

It can be seen from Figure 17 that the height of cotton plants in the ground observation stage, from the initial bud stage to the full bud stage of cotton growth stage, showed a rapid growth trend, and the growth rate of cotton plant height from the full bud stage to the flowering stage decreased. The growth rate of cotton plant height from full bud stage to flowering stage was significantly higher than that from initial bud stage to full bud stage. From the above analysis results, it can be seen that the average plant height of cotton in the sample unit obtained by DSM difference method is a quantitative expression of cotton canopy plant height, but there is still a certain deviation from the ground observation value. Figure 18 shows the distribution of the difference between the mean plant height of the sample units observed on the ground and the mean plant height extracted from the DSM difference method.

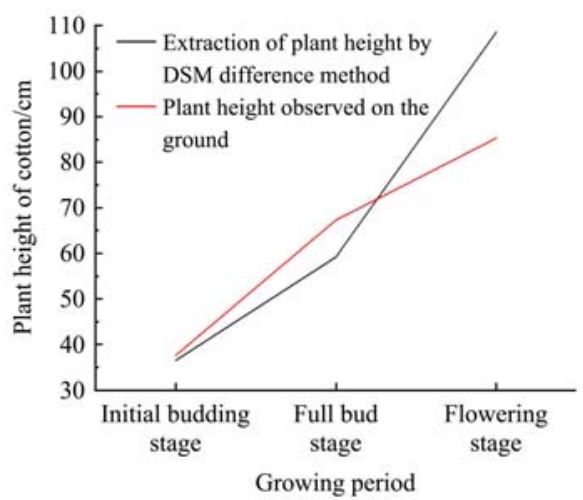

Figure 17 Line chart of cotton plant height statistical

It can be seen from Figure 18 that there is a certain deviation between the plant height of cotton extracted by DSM difference method in three periods and the ground observation plant height. The specific performance is that the plant height extraction error of cotton flowering period is the largest, followed by the full bud stage, and the plant height extraction error of cotton initial bud stage is smaller. Cotton is a multi branch crop. The cotton pixel extracted from DOM is a mixed pixel, not only the highest part of cotton canopy. Therefore, the cotton plant height extracted by DSM difference method is a comprehensive plant height of mixed pixel The overall plant height of cotton in full bud stage extracted by DSM difference method is lower than that observed on the ground, which is the main reason for the error of plant height extracted in full bud stage; from full bud stage to flowering stage, due to a lot of field management work such as irrigation, weeding and fertilization, the land in the field is not smooth, and the terrain under the corresponding cotton plant is increased, so it is necessary to use the DSM difference method The plant height extracted by DSM difference method was significantly higher than that observed on the ground.

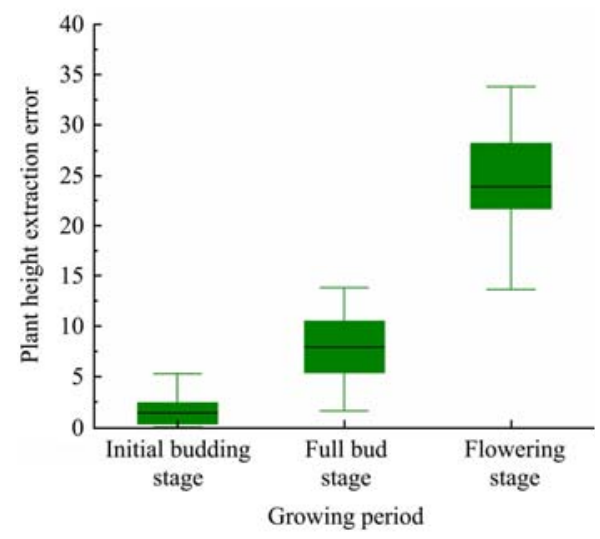

Figure 18 Distribution of cotton plant height extraction error

In order to more clearly compare the extraction effect of plant height of different varieties of cotton based on DSM difference method at different growth stages, the ground observation plant height was selected as the true value, and the DSM difference method was verified by $R^{2}$, RMSE and nRMSE evaluation indexes. The verification results of cotton initial bud stage, full bud stage and flowering stage were shown in Figure 18.

It can be seen from Figure 19 that the determination coefficients 
of cotton plant height in three periods extracted by DSM difference method are all greater than 0.75 , the corresponding RMSE are all less than $5 \mathrm{~cm}$, and the fluctuation range of nRMSE in three periods is small, which indicates that DSM difference method has better plant height estimation ability, and can be used to complete the work of cotton plant height extraction in initial bud stage, full bud stage and flowering stage.
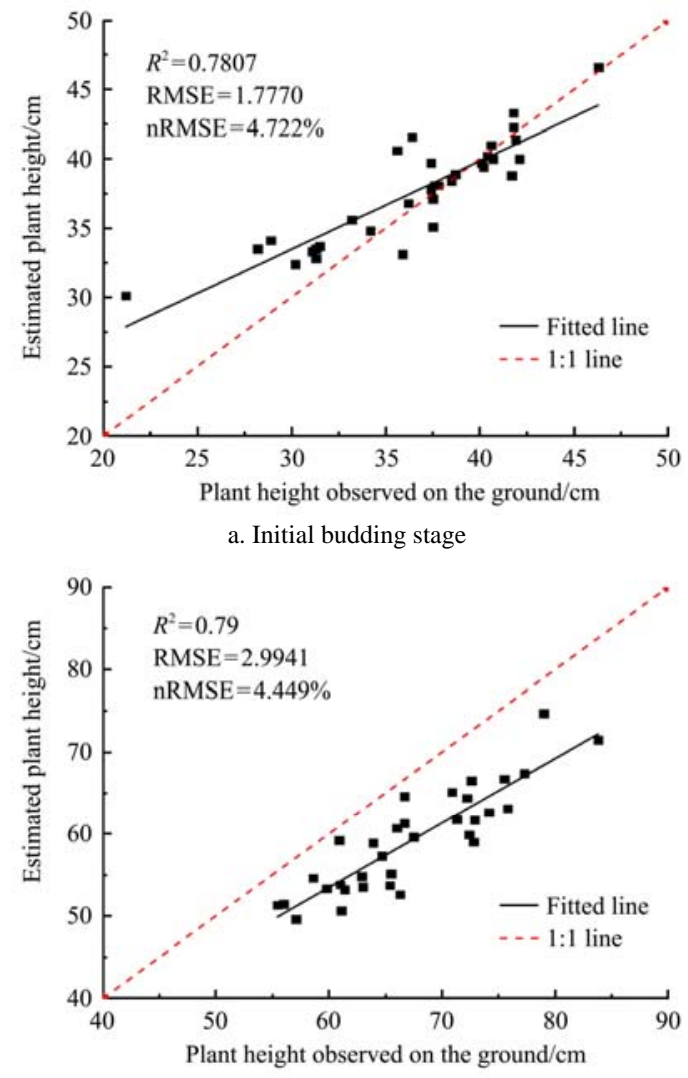

b. Full bud stage

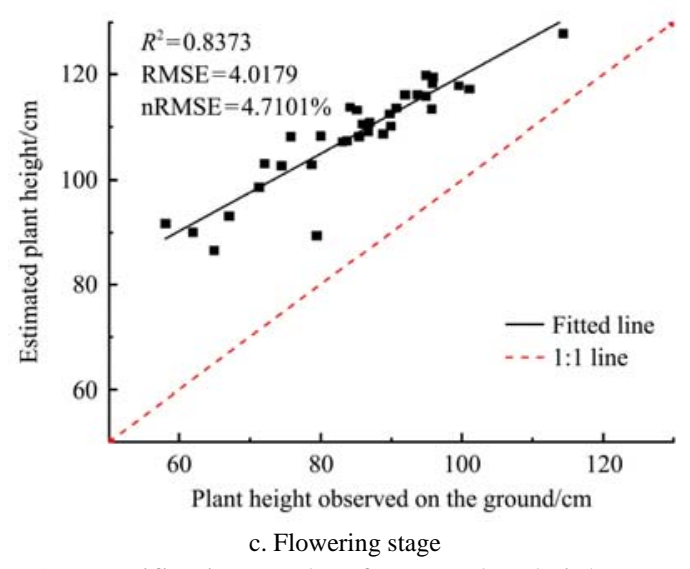

Figure 19 Verification results of cotton plant height extraction accuracy based on DSM difference method

In order to test the overall monitoring ability of cotton plant height from initial bud stage to full bud stage by DSM difference method, combined with different varieties and different growth stages, the fitting models of cotton growth stages of initial bud stage, full bud stage and flowering stage were constructed. Under the regression relationship, $R^{2}=0.8489$, RMSE $=8.3539$, nRMSE $=13.22 \%$ were calculated. The results showed that the fitting effect between the predicted value and the actual value in the three growth periods of cotton was better. The linear results of cotton plant height in three growth periods are shown in Figure 20.

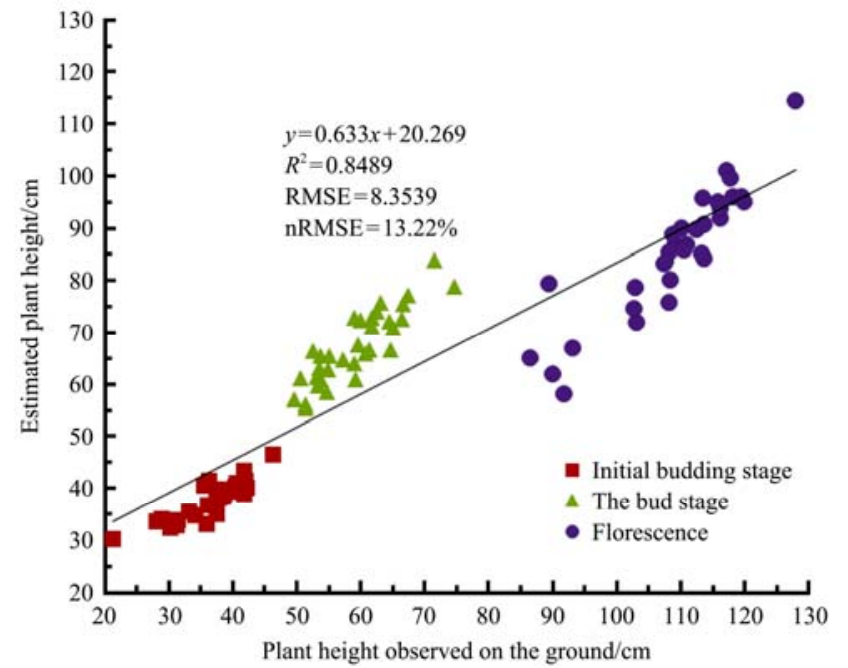

Figure 20 Fitting results of cotton plant height extraction based on DSM difference method and Ground Observed Plant Height

When using DSM difference method to obtain four plant heights of cotton, it is found that the extraction accuracy of cotton plant height is greatly affected by the mosaic accuracy of cotton image in each period and the division of region of interest of samples. This chapter summarizes that if the alignment precision and point cloud generation control options are ultra-high precision in the process of cotton image stitching, the image DSM precision of cotton stitching is higher. When selecting the region of interest of cotton, it can be selected according to the degree of light and dark consistency in the gray image of cotton DSM difference, which can effectively reduce the extraction error of cotton plant height.

\subsection{Distribution map of cotton plant height}

After extracting the plant height of cotton at initial bud stage, full bud stage and flowering stage by DSM difference method, in order to see the growth trend of cotton in each period more clearly and intuitively, and facilitate farmers' field irrigation and fertilization operation, it is of great significance to generate the spatial distribution of cotton plant height in each growth period. Before the generation of cotton plant height distribution map, the vector file of vegetation coverage extracted by TRVI combined with vegetation index threshold method was generated. The vegetation vector files of cotton initial bud stage, full bud stage and flowering stage were converted into regions of interest for vegetation clipping in DSM gray image, and the pixel value outside the vegetation was set to 0 . Then the spatial distribution map of plant height at initial bud stage, full bud stage and flowering stage of cotton was generated (as shown in Figure 21).

It can be seen from Figure 21 that the field soil has been removed from the cotton vegetation, and the soil value is 0 , showing white; the plant height of cotton in the initial bud stage is mainly concentrated in the range of $0.2 \sim 0.4 \mathrm{~m}$, which is consistent with the actual cotton growth height; the plant height of cotton in the full bud stage is mainly concentrated in the range of $0 \sim 0.5 \mathrm{~m}$ and $0.5 \sim 0.7 \mathrm{~m}$, which is slightly lower than the actual field cotton growth height; the plant height of cotton in the flowering stage is mainly concentrated in the range of $0.7 \sim 0.9 \mathrm{~m}$ Although the plant height of full bud stage and flowering stage extracted by DSM difference method has a certain deviation, it has a good fitting effect with cotton plant height. Therefore, the plant height grade distribution map of cotton in three stages can provide a reference for field cotton management. 


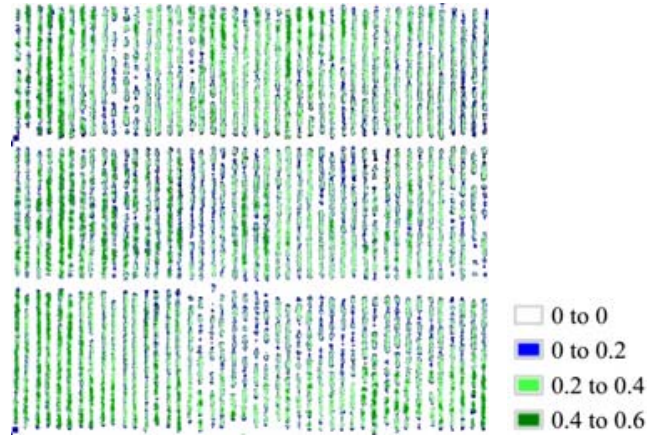

a. Plant height distribution map of cotton at initial bud stage

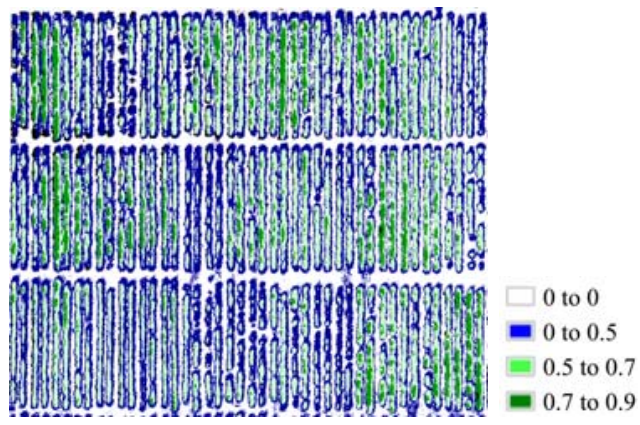

b. Distribution map of plant height in full bud stage of cotton

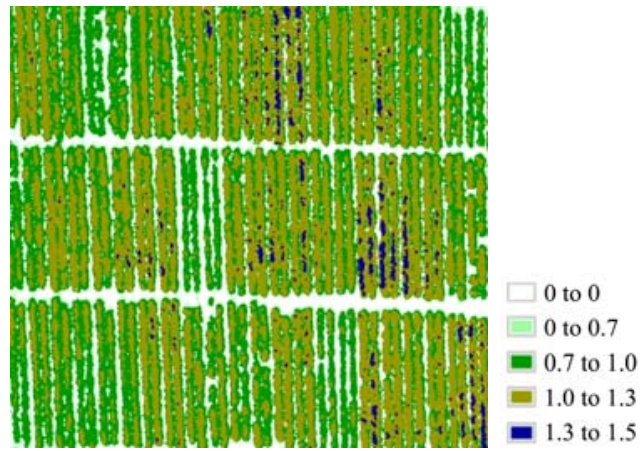

c. Distribution map of plant height at flowering stage of cotton

Figure 21 Spatial distributions of cotton plant height

\section{Conclusions}

The visible images taken by UAV were used to obtained DOM and DSM stitched, and the vegetation cover extraction model and cotton plant height extraction model were established respectively based on DOM and DSM. The conclusions are as follows.

(1) The visible images of cotton at each period taken by UAV were stitched to obtain its orthophoto, and based on this, the vegetation index Red-green characteristic vegetation index, TRVI, was constructed, and the cotton vegetation cover extraction model was established based on the vegetation index threshold method. The support vector machine classification results were used as true values, and $R^{2}$, RMSE and nRMSE were used as evaluation indexes to verify the accuracy of cotton vegetation cover. The results showed that the cotton vegetation cover extraction model worked best at the flowering and boll stages $\left(R^{2}=0.9942\right.$ and $\left.R^{2}=0.9775\right)$, and the $R^{2}$ of the remaining periods were higher than 0.8 , and the model worked well. Finally, the model extracted that the vegetation cover of cotton in the four periods were $29.05 \%$, 55.96\%, $78.70 \%$ and $91.74 \%$, respectively.

(2) A cotton plant height extraction model based on DSM difference method was established using visible light images. The DSM differential method was used to obtain the plant height parameters of cotton at the first budding stage, the full bud stage and the flowering stage, and the results extracted by the DSM differential method were verified by using the actual measured plant height of cotton in the field. The results showed that the plant height extraction model based on DSM difference method had the best extraction effect on flowering stage $\left(R^{2}=0.8373\right)$, and the $R^{2}$ of early bud and full bud were greater than 0.78 , which was better.

(3) The cotton plant height class distribution maps generated by combining the TRVI vegetation index threshold method and DSM difference method in the experimental area can provide field managers with an understanding of the growth condition of cotton and provide guidance for subsequent management.

Although the developed framework has been initially validated through experiments and its good results have high accuracy, but there is still much room for future research, as summarized below.

(1) The accuracy of cotton plant height extracted by DSM difference method at initial bud stage, full bud stage and flowering stage is greatly affected by image mosaic technology. In the future, ground control points will be added, and the accuracy of image mosaic can be improved.

(2) The cotton plant height class distribution map generated in this study can be further used to guide the cotton topping work.

\section{Acknowledgments}

We are grateful to Dean Lan Yubin, Professor Wang Shizhou of Shandong University of Technology, Director Dong Hezhong, Director Zhang Xiaojie, Webmaster Xu Shizhen and Teacher Zhang Yanjun of Shandong Provincial Cotton Research Center for providing the cotton experimental field and help. This research was supported by the Natural Science Foundation of China (31971787).

\section{[References]}

[1] Pei X M, Zhang Y T Liu C, et al. Study on the development of cotton production mechanization in China. Agricultural machinery science and technology promotion, 2011; 1, 19-22. doi: CNKI:SUN:NJTG.0.201101-008

[2] Luo H X, Kan Y B, Wang L L, et al. Application research status of crop diseases and insect pests based on hyperspectral remote sensing technology. Guangdong Agricultural Sciences, 2012; 39(18): 82-86. doi: 10.16768/ j.issn.1004-874x.2012.18.035

[3] Lan Y, Zhang H, Lacey R, et al. Development of an Integrated Sensor and Instrumentation System for Measuring Crop Conditions. development, 2009. doi: 10.1007/s004290050244

[4] Cui M N, Dai J G, Wang S H, et al. Identification method of cotton spider mite based on UAV multispectral image. Xinjiang Agricultural Sciences, 2018; 55(8): 1457-1466. doi: 10.6048/j.issn.10014330.2018.08.011

[5] Huang H, Deng J, Lan Y, et al. A fully convolutional network for weed mapping of unmanned aerial vehicle (UAV) imagery. PLoS ONE, 2018; 13(4): e0196302. doi: 10.1371/journal.pone.0196302

[6] Wang S S, Wang S, Zhang $\mathrm{H}$, et al. Soybean field weed recognition based on light sum-product networks and UAV remote sensing images. Journal of Agricultural Engineering, 2019; 35(06): 89-97. doi: 10.11975/ j.issn.1002-6819.2019.06.010

[7] Detar W R. Yield and growth characteristics for cotton under various irrigation regimes on sandy soil. Agricultural water management, 2008; 95(1): 69-76. doi: 10.1016/j.agwat.2007.08.009

[8] Zhang Z T, Chen J Y, Liu J M, et al. Effect of TM6 on monitoring soil moisture content by remote sensing principal component analysis. Water saving irrigation, 2010; 04, 20-23. doi: CNKI: SUN:JSGU.0.2010-04-006

[9] Zhu Z H, Wang W Z, Liu S C, et al. Application of near infrared diffuse reflectance spectroscopy in quality identification of Crop Germplasm Resources. Modern scientific instruments, 2006; 000(001): 63-66. doi: 10.3969/j.issn.1003-8892.2006.01.021

[10] Zhang B H, Li J B, fan S X, et al. Principle and application of hyperspectral imaging technology in nondestructive testing of fruit and vegetable quality and safety. Spectroscopy and spectral analysis, 2014; 34(10): 2743-2751. doi: CNKI:SUN:GUAN.0.2014-10-033.

[11] Zhao J, Quan P, Minjuan M A, et al. Comparative analysis of spectral 
nondestructive prediction models for Fuji apple harvest maturity. Transactions of the Chinese Society for Agricultural Machinery, 2018; 12(49): 47-354. doi: 10.6041/j.issn.1000-1298.2018.12.041

[12] Pei Z Y, Yang B J. Spatiotemporal feature extraction of multi temporal normalized vegetation index NDVI and design of crop growth model. Journal of agricultural engineering, 2000; (05): 24-26. doi: 10.3321/ j.issn:1002-6819.2000.05.005

[13] Tao H L, Xu L J, Feng H K, et al. Winter wheat growth monitoring based on Hyperspectral growth index of UAV. Journal of agricultural machinery, 2020; 51(02): 180-191. doi: 10.6041/j.issn.1000-1298.2020. 02.020

[14] Trooien T P, Heermann D F. Measurement and simulation of potato leaf area using image processing. I. Model development. Transactions of the Asae, 1992; 35(5): 1709-1712. doi: 10.13031/2013.28787

[15] Shen C C, Zhu Y J, Chen K, et al. Mapping QTLs for heading date and plant height using magic population and Germplasm Resources in rice. Beijing: Acta crop, 2017, 43(011): 1611-1621.

[16] Zhang X Y, Wu B Z, Wu K X, et al. Mapping of QTLs for Heading Date and Plant Height Using MAGIC Populations of Rice. Acta phytonutrition and fertilizer, 2019; 25(7): 1239-1246. doi: 10.3724/SP.J.1006.2017. 01611

[17] Juliane B, Andreas B, Simon B, et al. Estimating biomass of barley using crop surface models (CSMs) derived from UAV-based RGB imaging. Remote Sensing, 2014; 6(11): 10395-10412. doi: 10.3390/rs61110395

[18] Niu Y, Zhang L, Zhang H, et al. Estimating Above-Ground Biomass of Maize Using Features Derived from UAV Based RGB Imagery. Remote Sensing, 2019; 11(11): 1261 . doi: 10.3390/rs11111261

[19] Wang P, Luo X W, Zhou Z Y, et al. Key technologies of remote sensing information acquisition based on micro UAV. Journal of agricultural engineering, 2014; 30(18): 1-12. doi: 10.3969/j.issn.1002-6819.2014. 18.001
[20] Su J, Yi D, Su B, et al. Aerial Visual Perception in Smart Farming: Field Study of Wheat Yellow Rust Monitoring. IEEE Transactions on Industrial Informatics, 2020. doi: 10.1109/TII.2020.2979237

[21] Su J Y, Liu C J, Coombes M, et al. Wheat yellow rust monitoring by learning from multispectral UAV aerial imagery. Computers and Electronics in Agriculture, 2018; 155, 157-166. doi: 10.1016/ j.compag.2018.10.017

[22] Qiao Z N, Ma J, Xu Y N. Application of UAV Remote Sensing in tree crown extraction. Forestry resource management, 2019; 1, 78-84. doi: 10.13466/j.cnki.lyzygl.2019.01.013

[23] Zhao Y J, Gong X C, Du W J, et al. Application of photoscan Pro software in UAV emergency aerial photography. Land and resources remote sensing, 2015, 107(04): 182-185. doi: 10.6046/gtzyyg.2015.04.27

[24] Niu Y, Zhang L, Han W, et al. Extraction method of winter whea coverage based on UAV remote sensing and vegetation index. Journal of agricultural machinery, 2018; 49(4): 212-221. doi: 10.6041/ j.issn.1000-1298.2018.04.024

[25] Li B, Liu R Y, Liu S H, et al. Winter wheat coverage change monitoring based on low altitude UAV Remote Sensing. Journal of agricultural engineering, 2012; 28(13): 160-165. doi: 10.3969/j.issn.1002-6819.2012. 13.026

[26] Tian Z, Fu Y, Liu S, et al. Fast classification method of crops based on UAV low altitude remote sensing. Transactions of the Chinese Society of Agricultural Engineering, 2013; 29(7): 109-116. doi: 10.3969/ j.issn.1002-6819.2013.07.014

[27] Vapnik V N. An overview of statistical learning theory. IEEE Transactions on Neural Networks, 1999; 10(5): 988-999. doi: 10.1109/ 72.788640

[28] Haralick R M, Shanmugam K, Dinstein I. Textural Features for Image Classification. Studies in Media and Communication, 1973, 6: 610-621. doi: 10.1109/72.788640. 